\title{
Developments in the Management of Type 1 and Type 2 Diabetes
}

\author{
An Expert Interview with Chantal Mathieu
}

Catholic University of Leuven, Belgium

DOl: https://doi.org/10.17925/EE.2018.14.2.13

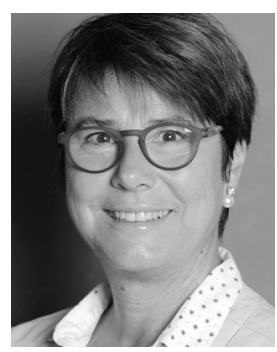

\begin{abstract}
Chantal Mathieu
Chantal Mathieu is Professor of Medicine at the Katholieke Universiteit Leuven, Belgium. She is Chair of Endocrinology at the University Hospital Gasthuisberg Leuven. Prof. Mathieu received her medical degree and PhD at the University of Leuven, where she subsequently completed training in internal medicine and endocrinology. Prof. Mathieu's clinical areas of interest include the organisation of diabetes care, and she is involved in several clinical trials in type 1 and type 2 diabetes. Her basic research is focused on the prevention of type 1 diabetes, effects of vitamin D on the immune system and diabetes, and functioning of the insulin-producing beta cell. Prof. Mathieu has authored or co-authored more than 350 peer-reviewed publications in international journals. In 2013, Prof. Mathieu received the prestigious InBev-Baillet Latour Prize for Clinical Research for her pioneering research on the pathogenesis of type 1 diabetes. She presently coordinates the INNODIA project on prevention and intervention in type 1 diabetes in Europe and is vice-president of the European Association for the Study of Diabetes (EASD) and Chair of Postgraduate Education at EASD.
\end{abstract}

\section{Keywords}

Type 1 diabetes, type 2 diabetes, management, care, insulin, glucose control, EASD

Disclosure: Chantal Mathieu has served on advisory panels, has been a speaker or received research support from Adocia, AstraZeneca, Boehringer Ingelheim, Bristol-Myers Squibb, Dianax, Eli Lilly, GSK, Intrexon, Janssen Pharmaceuticals, Hanmi Pharmaceuticals, Merck Sharp \& Dohme, Novartis, Novo Nordisk, Pfizer, Roche Diagnostics and Sanofi.

Review Process: This is an expert interview and as such has not undergone the journal's usual peer review process.

Acknowledgements: Medical writing assistance was provided by Katrina Mountfort at Touch Medical Media.

Authorship: All named authors meet the International Committee of Medical Journal Editors (ICMJE) criteria for authorship of this manuscript, take responsibility for the integrity of the work as a whole, and have given final approval to the version to be published.

Open Access: This article is published under the Creative Commons Attribution Noncommercial License, which permits any non-commercial use, distribution, adaptation and reproduction provided the original author(s) and source are given appropriate credit. () The Authors 2018

Received: 10 July 2018

Published Online: 17 July 2018

Citation: European Endocrinology. 2018;14(2):13-4

Corresponding Author: Chantal Mathieu,

Dept Endocrinology UZ Gasthuisberg Herestraat 493000 Leuven, Belgium. E: chantal.mathieu@uzleuven.be
$\mathrm{P}$ oor glucose control resulting from diabetes is responsible for the deaths of millions of people worldwide each year, and reduces the quality of life for many more. As a result, research continues for new glucose-lowering drugs, as well as improved ways to manufacture and deliver insulin. In this expert interview, Chantal Mathieu, Professor of Medicine at the Catholic University of Leuven, Belgium, discusses some of the latest developments in the management of both type 1 (T1D) and type 2 (T2D) diabetes.

\section{Q. How does Fiasp differ from other fast-acting mealtime insulins?}

Fiasp ${ }^{\circledR}$ (insulin aspart; Novo Nordisk, Bagsværd, Denmark) is the first of the next generation of faster-acting mealtime insulin analogues. We made a huge step several years ago when we moved from the regular human insulin that was injected at mealtimes to the fast-acting analogues we know today. These include Humalog ${ }^{\circledR}$ (insulin lispro; Lilly, Indianapolis, IN, US), NovoLog ${ }^{\circledR}$ (insulin aspart; Novo Nordisk, Bagsværd, Denmark) and Apidra ${ }^{\circledR}$ (insulin glulisin; Sanofi-Aventis, Paris, France). This has resulted in a more rapid appearance of insulin in the blood after injection and a better coverage of the mealtime excursion in glucose that is associated with T1D, resulting in fewer peaks and troughs in insulin levels 3-4 hours from injection of the insulin at mealtime. Following the development of continuous glucose monitoring (CGM) systems, we discovered that these fact-acting mealtime insulins were still too slow and that peaks and troughs in glucose levels still occur after meals. We discovered that these insulins should ideally be injected not immediately before meals but 10-20 minutes before the meal. However, this impacts on the day-to-day life of our patients; for example, this is not convenient before breakfast. We also found that many patients inject during their meal or even after the meal if there is uncertainty about what patients will eat (for example children and elderly patients). So, the industry has been working on extra-fast insulins. These have altered the excipients in which the insulin aspart is solubilised. They have added L-arginine and vitamin $B$, two natural agents that are approved by the European Medicines Agency and the US Food and Drug Administration. These facilitate the rapid movement of insulin through the capillaries into the blood. The pharmacokinetic profiles show a 5-minute shift to the left. This will have a great impact on the quality of life of our patients as it will allow them to inject insulin at a time closer to the meal, and will better cover glucose excursions.

\section{Q. Are there any limitations of Fiasp?}

Not really. Studies have compared injections of Fiasp immediately before a meal with insulin aspart and found that Fiasp gives smaller glucose excursions as well as a small but statistically significant difference (around 0.1\%) in glycated haemoglobin (HDA1C) after 6 months and 1 year. ${ }^{1,2}$ We have also demonstrated that injection of Fiasp within 20 minutes after starting a meal gives the same effect as if it was injected before the meal. This is useful if people forget their injections or if it is not possible to predict what a patient will eat. 


\section{Q. What clinical evidence supports the use of adjunct glucose-lowering agents in type 1 diabetes?}

For many years we have been trying to give our patients with T1D the same glucose lowering agents that are used in patients with T2D, with the aim of helping them reach better glucose control by supplementing their insulin. We have been using off-label metformin for a long time, because increasing the insulin dose in patients with T1D results in weight gain and hypoglycaemia. Short-term studies have shown insulin-sensitising benefits of metformin, improvements in $\mathrm{HbA} 1 \mathrm{C}$ and reductions in weight gain. ${ }^{3}$ However, longer-term studies show that the beneficial effect of metformin is lost after a year, so metformin is only useful in the short term. ${ }^{3}$

Glucagon-like peptide 1 receptor agonists such as liraglutide have also been investigated due their insulin-independent actions and weightlowering effect. Two large adjunct studies in patients with T1D have shown that adding liraglutide to intensive insulin therapy showed an improved effect on $\mathrm{HbA} 1 \mathrm{C}$ with less insulin and with weight reduction. ${ }^{4,5}$ However, by 1 year the effect was diminished. We also found that if the insulin dose is not adapted downwards rapidly enough, there was an increased risk of hypoglycaemia. In addition, the findings suggested a possible increased risk of diabetic ketoacidosis (DKA). In a substudy ${ }^{4}$ of patients who still had beta cells left, there were good improvements in $\mathrm{HbA} 1 \mathrm{C}$ and weight without these risks. ${ }^{4}$

The sodium-glucose co-transporter-2 (SGLT2) system is an appealing insulin-independent method of glucose lowering in terms of weight loss and more stable glucose control. Studies investigating SGLT2 and combined SGLT1/2 inhibitors have shown improvements in HbA1C, reductions in insulin dose and weight reduction. ${ }^{6}$ CGM studies have also shown a more stable glucose profile. ${ }^{7}$ There is no increase in severe hypoglycaemia but some increased risk of DKA has been seen depending on the study. Recently published studies have shown increases in DKA up to $3 \%{ }^{8,9}$ Therefore, the use of SGLT1/2 and SGLT2 inhibitors in patients with T1D will have to be accompanied by strict education on DKA, how to anticipate its onset and manage raised ketone levels. An increased risk of genital infections has also been seen. Overall, the SGLT inhibitors make elegant adjunct therapies and patients are happy using them, but they will only be accepted if we can keep the risk of DKA manageable.

\section{Q. How are SGLT1/2 and SGLT2 inhibitors likely to fit into the treatment paradigm for type 1 diabetes?}

The ideal patient for these therapies would be one who, despite intensive insulin therapy and education, does not reduce his/her HbA1c to target or has undesired weight gain in doing so. My ideal patient would have an $\mathrm{HbA} 1 \mathrm{c}$ level of $8-8.5 \%$ and a body mass index over 25 . The only other requirement is to understand the risk and management of DKA.

\section{Q. What key topics are you looking forward to at this year's European Association for the Study of Diabetes meeting?}

I am looking forward to the presentation of the new consensus statement between the American Diabetes Association (ADA) and European Association for the Study of Diabetes (EASD) on glucoselowering agents in T2D. This was presented as first draft at ADA, and then was opened to comments, with the final presentation and simultaneous publication at EASD. There will be European Society of Cardiology/EASD guidelines specifically on people with cardiovascular disease and diabetes. The meeting will also feature presentations on cardiovascular outcome studies and adjunct studies. I think it will be an outstanding meeting and one to attend.
1. Mathieu C, Bode BW, Franek E, et al. Efficacy and safety of fastacting insulin aspart in comparison with insulin aspart in type 1 diabetes (onset 1): A 52-weck, randomized, treat-to-target, phase III trial. Diabetes Obes Metab. 2018;20:1148-55.

2. Russell-Jones D, Bode BW, De Block C, et al. Fast-acting insulin aspart improves glycemic control in basal-bolus treatment for type 1 diabetes: results of a 26-Week multicenter, activecontrolled, treat-to-target, randomized, parallel-group trial (onset 1). Diabetes Care. 2017;40:943-50.

3. Staels F, Moyson C, Mathieu C. Metformin as add-on to intensive insulin therapy in type 1 diabetes mellitus. Diabetes Obes Metab. 2017;19:1463-7.
4. Mathieu C, Zinman B, Hemmingsson JU, et al. Efficacy and safety of liraglutide added to insulin treatment in type 1 diabetes: The ADJUNCT ONE Treat-To-Target Randomized Trial. Diabetes Care. 2016:39:1702-10.

5. Ahrén B, Hirsch IB, Pieber TR, et al. Efficacy and safety of Aren, $B$ irsch $B$, liraglutide added to capped insulin treatment in subjects with type 1 diabetes. The ADJUNCT TWO Randomized Trial. Diabetes Care. 2016;39:1693-701.

6. Dandona P, Mathieu C, Phillip M, et al. Efficacy and safety of dapagliflozin in patients with inadequately controlled type 1 diabetes (DEPICT-1): 24 week results from a multicentre, double-blind, phase 3 , randomised controlled trial. Lancet
Diabetes Endocrinol. 2017:5:864-76.

. Garg SK, Henry RR, Banks P, et al. Effects of sotagliflozin added to insulin in patients with type 1 diabetes. N Eng/ J Med. 2017:377:2337-48.

8. Danne T, Cariou B, Banks P, et al. HbA1C and hypoglycemia reductions at 24 and 52 weeks with sotagliflozin in combination with insulin in adults with type 1 diabetes: the European with insulin in adults with type 1 diabetes: the European
inTandem2 Study. Diabetes Care. 2018;pii: dc180342;

9. Mathieu C, Dandona P, Gillard P, et al. Efficacy and safety of dapagliflozin in patients with inadequately controlled type 1 diabetes (the DEPICT-2 Study): 24-week results from a randomized controlled trial. Diabetes Care. 2018;iii: dc180623. 